\title{
Life satisfaction, health, self-evaluation and sexuality in current university students of sport sciences, education and natural sciences
}

\author{
Martin Sigmund $^{1, *}$, Jana Kvintová ${ }^{2}$, Hana Hřebičcková ${ }^{1}$, Michal Šafár $\check{1}^{1}$, and Dagmar Sigmundová1 \\ ${ }^{1}$ Faculty of Physical Culture, Palacký University, Olomouc, Czech Republic; ${ }^{2}$ Faculty of Education, Palacký University, \\ Olomouc, Czech Republic
}

Copyright: (C) 2014 M. Sigmund et al. This is an open access article licensed under the Creative Commons Attribution License (http://creativecommons.org/licenses/by/4.0/).

\begin{abstract}
Background: Lifestyle and health of an individual are influenced by many factors; a significant factor is life satisfaction. Life satisfaction is understood as a multidimensional construct closely related to the area of personal wellbeing and quality of life. Life satisfaction in university students represents one of the determinants of good health, high motivation for studying, work productivity, satisfactory interpersonal relationships and overall healthy lifestyle. Objective: The main objective of the present study is to identify and compare the level of overall life satisfaction and selected components of health, self-evaluation and sexuality in current university students with respect to their study specialization. Methods: The study included a total of 522 students from Palacký University. These were students from the Faculty of Physical Culture $(n=118)$, Faculty of Education $(n=218)$ and Faculty of Science $(n=186)$. In terms of age, the study focused on young adults aged 19 to 26. To assess the current level of life satisfaction, the research study used a standardized psychodiagnostic tool - Life Satisfaction Questionnaire (LSQ). The used diagnostic methods are fully standardized and contain domestic normative values. Statistical result processing was conducted using the Statistica programme v10.0. Results: The highest level of overall life satisfaction was revealed in university students of sport sciences. In comparison with the students of education and students of natural sciences the difference is significant. Satisfaction with health among the students of sport sciences is significantly higher than in the students of education ( $p \leq .001 ; d=0.53)$ and the students of natural sciences $(p \leq .05 ; d=0.38)$. Similar results were found in the area of satisfaction with own person and self-evaluation, where the values of the students of sport sciences were significantly higher compared with the students of education $(p \leq .001 ; d=0.39)$ and the students of natural sciences $(p \leq .001 ; d=0.30)$. In the area of sexuality we revealed significantly higher values in the students of sport sciences compared with the students of natural sciences $(p \leq .05 ; d=0.32)$. Conclusion: The results of the present study indicated that current university students who study sports sciences assess their life satisfaction significantly higher compared with the students of other specializations. The results of the study indicated a positive correlation between physical activity of current university students and the subjectively perceived level of life satisfaction, health, self-evaluation and sexuality.
\end{abstract}

Keywords: quality of life, health psychology, study specialization, adults, physical activity

\section{Introduction}

University students represent a specific population group. From a developmental point of view the period of university study is characterised by reaching maturity in the somatic, mental, emotional and social areas. Recently there has been a growing interest of the professional community in the issue of lifestyle and health of university students because they should represent

\footnotetext{
* Address for correspondence: Martin Sigmund, Department of Recreology, Faculty of Physical Culture, Palacký University, tř. Míru 115, 77111 Olomouc, Czech Republic. E-mail: martin.sigmund@upol.cz
}

national capital and future investment for society (Adlaf, Gliksman, Demers, \& Newton-Taylor, 2001; Batrymbetova, 2008; Dyrbye, Thomas, \& Shanafelt, 2006; Geoff, Lovell, El Ansari, \& Parker, 2010; Hamaideh, 2011; Linhartová, 2008; Martikainen, 2009; Menclová \& Baštová, 2005; Stallman, 2008). An individual in this age category leaves the period of adolescence and enters the period of adulthood. These developmental facts bring positive as well as negative confrontations with life reality, which is reflected in the overall level of life satisfaction and health.

Generally, the population between twenty and thirty years of age presents a group with the lowest morbidity 
and mortality. However, it should be stated that the results of research studies analysing risk factors affecting university population highlight that the health of university students is generally worse than the health of non-studying population of the same age. Similarly, the prevalence of mental distress is higher among university students compared with working non-student population of the same age (Adlaf, Gliksman, Demers, \& Newton-Taylor, 2001; Dyrbye, Thomas, \& Shanafelt, 2006; Roberts, Golding, Towell, \& Weinreb, 1999).

Significant determinants of lifestyle and health are represented by life satisfaction and its components. The general concept of satisfaction covers a certain degree of personal balance, personal happiness and often personal impact and inclusion in the society. In common understanding however, this concept is simply associated with certain mental states after reaching specific goals and is a certain result of satisfying specific needs of an individual. Life satisfaction is a psychological construct that has become an increasingly important outcome measure in medicine and healthcare (Daig, Herschbach, Lehmann, Knoll, \& Decker, 2009). Life satisfaction is a dynamic phenomenon closely associated with human motivation and human driving and activating components. In our paper, life satisfaction is considered a multidimensional construct closely related to and frequently overlapping the areas of personal wellbeing and quality of life (Proctor, Linley, \& Maltby, 2009). There is no single factor that would influence the level of life satisfaction in isolation. Satisfaction in individual areas of life and life satisfaction are influenced by common as well as specific factors. In general, this concept is an effort to achieve such quality of life that enables an individual or a group to experience a feeling that their needs have been fulfilled and that they are not deprived of any opportunities to achieve happiness and life fulfilment (Kahneman, Diener, \& Schwarz, 2003).

Life satisfaction in university students is one of the predictors of good health, high motivation for studying, work productivity, satisfactory interpersonal relationships and healthy lifestyle. Significant factors influencing the level of life satisfaction in individuals in the period of young adulthood, which is the typical age of university students, include subjective health assessment, level of self-evaluation and sexual behaviour as a significant psychosocial health determinant (Crooks \& Baur, 2010; Frederick, Peplau, \& Lever, 2006; Ogden, 2012).

A significant factor influencing an individual's health, quality of life and life satisfaction is also physical activity (Bize, Johnson, \& Plotnikoff, 2007; Grant, Wardle, \& Steptoe, 2009; Joseph, Royse, Benitez, \& Pekmezi, 2014; Mikolajczyk et al., 2008; Perales, del
Pozo-Cruz, del Pozo-Cruz, \& del Pozo-Cruz, 2014; Penedo \& Dahn, 2005; Schnohr, Kristensen, Prescott, \& Scharling, 2005). Physical activity has a short-term as well as long-term favourable effect on mental wellbeing, with a particular influence on self-respect, anxiety, depression, tension, stress perception (Dunn, Trivedi, \& O’Neal, 2001; Kirkcaldy, Shephard, \& Siefen, 2002; Penedo \& Dahn, 2005; Piko \& Keresztes, 2006). It can be anticipated that university students of sport sciences will report more physical activity compared with the students of other specializations. In this context, our survey included a question about the level of overall life satisfaction and the monitored components in current university students of physical culture in comparison with university students of education and natural sciences.

The main objective of the present study is to identify and compare the level of overall life satisfaction and selected components of health, self-evaluation and sexuality in current university students with respect to their study specialization. The emphasis is put on a comparison between a group of university students studying sport sciences and a group of non-sport sciences students. Another significant aspect is a transfer to the area of practical implementation in the context of work with university students, particularly in the area of educational and psychological university counselling.

\section{Material and methods}

\section{Subjects}

The study involved a total of 522 students from three faculties of Palacký University. Specifically the students were from the Faculty of Physical Culture (students of sport sciences), Faculty of Education (students of education) and Faculty of Science (students of natural sciences) (Table 1). The survey and data collection was conducted according to a time plan in 2011. Administration of this questionnaire was carried out at predetermined times during psychological seminars. Students were offered the possibility of active participation in the research study. Assuming positive informed consent and voluntary participation, students completed the test battery, which included the evaluation of the level of life satisfaction and their components. Comprehensive administration of the questionnaires was carried out by one person with the appropriate psychological education and practice.

In the context of our research a present university student was any individual properly enrolled as a fulltime student whose age was adequate to the respective university grade. In terms of age, the study involved 
young adults aged 19 to 26 . Most students were in the categories of 20,21 and 22 years of age $(\Sigma n=420)$. With respect to age, these age categories represent in total more than $80 \%$ of the whole sample.

Table 1

Characteristics of study participants $(N=522)$

\begin{tabular}{ll}
\hline & $\begin{array}{c}\text { Number of participants } \\
\text { (men/women) }\end{array}$ \\
\hline Students of sport sciences & $118(50 / 68)$ \\
Students of education & $218(11 / 207)$ \\
Students of natural sciences & $186(70 / 116)$ \\
Total & $522(131 / 391)$ \\
\hline
\end{tabular}

\section{Ethical aspects}

The study was conducted in compliance with ethical aspects. The design of research and permission to conduct this research was provided on the basis of consideration of the ethical commission of the Department of Psychology and Abnormal psychology, Faculty of Education, Palacký University in Olomouc. The survey involved adult individuals on a voluntary basis. Each participant was informed of a possibility to terminate participation at any stage without giving any reason. All data was processed anonymously, it was impossible to identify specific probands. The survey participants consented to anonymous data processing and use for scientific purposes.

\section{Psychological assessment}

To assess the current level of life satisfaction, the research study used a standardized psychodiagnostic tool - Life Satisfaction Questionnaire (LSQ) (Rodná \& Rodný, 2001). The Czech version of the LSQ is based on the original German questionnaire Fragebogen zur Lebenszufriedenheit (FLZ) (Fahrenberg, Myrtek, Schumacher, \& Brähler, 2000). The LSQ is designed for standardized description of inter-individual and intra-individual life satisfaction variability. The questionnaire aims at the assessment of overall life satisfaction and its individual components: health, work and employment, finance, leisure time, partnership, relationship with own children, own person, sexuality, friends and acquaintances, living.

Each of the specified items contains seven statements. For each statement in each item the proband tries to express the current level of satisfaction by selecting on a seven-grade scale. 1 = very dissatisfied, $7=$ very satisfied. The overall value of life satisfaction is represented by the sum of gross score values in the seven defined items; work and employment, partnership and relationship with own children are not taken into account (Rodná \& Rodný, 2001). The health, own person and sexuality was elaborated and analysed in more detail. All subscales were selected due to the fact that the authors monitor factors closely associated with the individual himself. Other components of life satisfaction may be more dependent on external factors. Life satisfaction items that have not been analyzed in detail, they are part of the overall level of life satisfaction in the monitored target group and in this context there were incorporated.

\section{Statistical analysis}

Statistical processing was conducted using the Statistica programme (Version 10; StatSoft, Inc., Tulsa, OK, USA). For each variable, basic statistical variables were calculated. Result processing was made using nonparametric statistical methods. Normality was assessed using the Shapiro-Wilk normality test. Analyzed data did not show the normal distribution. To assess the differences between independent groups, the MannWhitney $U$ test was used. The level of statistical significance was tested at $p \leq .05 ; p \leq .01 ; p \leq .001$. The effect size is expressed in $d$ values, where $d$ is Cohen's coefficient for effect size defined as a difference between two means divided by a standard deviation for the data. The most frequent assessment of effect size $d$ is 0.2 - small effect, 0.5 - moderate effect and 0.8 - large effect (Cohen, 1988; Cortina \& Nouri, 2000; Thomas, Nelson \& Silverman, 2011).

\section{Results}

The results of the study include the observed values of overall life satisfaction in selected components (health, own person, sexuality) in current university students of sport sciences and students of education and students of natural sciences. The resulting data of the monitored variables are compared especially in the context of selected study specializations.

The highest level of overall life satisfaction was observed in university students of sport sciences. A comparison with the students of education and students of natural sciences revealed significant values with medium values of effect size (Table 2). In students of sport sciences the highest values of subjective satisfaction were observed in the components of health, own person and sexuality compared with the students of education and natural sciences. Satisfaction with own health in the students of sport sciences was significantly higher compared with the students of education $(p \leq .001 ; d=0.53)$ and the students of natural sciences $(p \leq .05 ; d=0.38)$. Similar results were achieved for the components of satisfaction with own person and 
Table 2

Overall index of life satisfaction, satisfaction with health, own person and sexuality in current university students with respect to study specialization

\begin{tabular}{cccccc}
\hline \multicolumn{1}{c}{ Mean $\pm S D$} & Range & Comp. & $p$ & $d$ \\
\hline Total & & & & & \\
S & $259.2 \pm 31.99$ & $188-354$ & S-E & .001 & 0.41 \\
E & $247.3 \pm 27.36$ & $173-316$ & S-N & .001 & 0.51 \\
N & $243.0 \pm 32.04$ & $155-316$ & E-N & NS & 0.15 \\
Health & & & & \\
S & $36.8 \pm 6.17$ & $19-49$ & S-E & .001 & 0.53 \\
E & $33.3 \pm 6.87$ & $11-49$ & S-N & .050 & 0.38 \\
N & $34.5 \pm 6.04$ & $21-49$ & E-N & NS & 0.19 \\
Own person & & & & .001 & 0.39 \\
S & $37.9 \pm 6.14$ & $15-48$ & S-E & .001 & 0.30 \\
E & $34.8 \pm 6.16$ & $7-46$ & S-N & NS & 0.02 \\
N & $34.9 \pm 5.92$ & $15-49$ & E-N & & \\
Sexuality & & & S-E & NS & 0.18 \\
S & $37.7 \pm 7.01$ & $16-49$ & S-N & .033 & 0.32 \\
E & $36.4 \pm 7.30$ & $12-49$ & E-N & NS & 0.14 \\
N & $35.4 \pm 7.44$ & $13-49$ &
\end{tabular}

Note. Comp. = comparison. $\mathrm{S}=$ students of sport sciences, $\mathrm{E}=$ students of education, $\mathrm{N}=$ students of natural sciences. NS = not significant.

self-evaluation where the values reported by the students of sport sciences were significantly higher compared with the students of education $(p \leq .001 ; d=0.39)$ and the students of natural sciences $(p \leq .001 ; d=0.30)$. In the area of sexuality we observed significantly higher values in the students of sport sciences compared with the students of natural sciences $(p=.033 ; d=0.32)$. Other differences in the values of sexual satisfaction in the monitored samples were insignificant (Table 2). In a detailed analysis of life satisfaction in the area of health in current university students, the highest values were scored by the students of sport sciences in six components out of seven (Table 3 ).

The assessment of satisfaction with own person revealed the highest values in the students of sport sciences. In all seven subcomponents of satisfaction with own person we observed the highest values in the students of sport sciences. At the same time, in six components out of seven we observed significant differences in comparison with the students of education and natural sciences (Table 4). In the area of sexuality and an analysis of its subcomponents one significant subcomponent was revealed that can be considered significant (Table 5). In terms of physical attractiveness the students of sport sciences felt significantly more attractive compared with the students of education and natural sciences. The students of sport sciences also reported significantly higher values in sexual performance and openness in communication in comparison with the students of natural sciences. In most other sexuality subcomponents we observed insignificantly values in the students of sport sciences.

\section{Discussion}

The issue of life satisfaction is mentioned in theoretical concepts as one of the conditions for effective psychological functioning of a human being (Ryan \& Deci, 2000). The theories are based particularly on humanistic thoughts of positive psychology, where satisfaction with one's life lies in the development of potential, self-realization and fulfilment of needs. Our study addresses the issue of life satisfaction and its selected components in current Czech university students. This research of a psychosocial nature highlights the lasting topicality and significance of concentrating on the life of university students. The main focus of the research is an analysis of their social, economic and study conditions in the context of quality of life and health. A social portrait of a Czech university student indicates that a typical student at a state university is single, childless, aged 22-24 years and lives in residence halls (Menclová \& Baštová, 2005). Moreover, these students 
Table 3

Comparison of life satisfaction in the area of subjective assessment of health in current university students with respect to study specialization

\begin{tabular}{|c|c|c|c|c|c|}
\hline Health components & Mean $\pm S D$ & Range & Comp. & $\mathrm{p}$ & $\mathrm{d}$ \\
\hline \multicolumn{6}{|c|}{ Somatic health condition } \\
\hline $\mathrm{S}$ & $5.58 \pm 1.19$ & $1-7$ & S-E & $<.001$ & 0.47 \\
\hline $\mathrm{E}$ & $4.96 \pm 1.41$ & $1-7$ & $\mathrm{~S}-\mathrm{N}$ & .003 & 0.38 \\
\hline $\mathrm{N}$ & $5.10 \pm 1.32$ & $1-7$ & $\mathrm{E}-\mathrm{N}$ & NS & 0.10 \\
\hline \multicolumn{6}{|l|}{ Mental condition } \\
\hline $\mathrm{S}$ & $5.42 \pm 1.20$ & $1-7$ & S-E & .035 & 0.95 \\
\hline $\mathrm{E}$ & $4.20 \pm 1.34$ & $1-7$ & $\mathrm{~S}-\mathrm{N}$ & .024 & 0.81 \\
\hline $\mathrm{N}$ & $4.39 \pm 1.31$ & $1-7$ & $\mathrm{E}-\mathrm{N}$ & NS & 0.14 \\
\hline \multicolumn{6}{|l|}{ Physical condition } \\
\hline $\mathrm{S}$ & $5.37 \pm 1.13$ & $2-7$ & S-E & $<.001$ & 0.28 \\
\hline $\mathrm{E}$ & $4.98 \pm 1.54$ & $1-7$ & $\mathrm{~S}-\mathrm{N}$ & $<.001$ & 0.28 \\
\hline $\mathrm{N}$ & $4.99 \pm 1.45$ & $1-7$ & $\mathrm{E}-\mathrm{N}$ & NS & 0.00 \\
\hline \multicolumn{6}{|l|}{ Mental performance } \\
\hline $\mathrm{S}$ & $5.31 \pm 1.19$ & $1-7$ & S-E & NS & 0.22 \\
\hline $\mathrm{E}$ & $5.05 \pm 1.17$ & $1-7$ & $\mathrm{~S}-\mathrm{N}$ & .016 & 0.27 \\
\hline $\mathrm{N}$ & $4.98 \pm 1.21$ & $1-7$ & $\mathrm{E}-\mathrm{N}$ & NS & 0.06 \\
\hline \multicolumn{6}{|l|}{ Immunity } \\
\hline $\mathrm{S}$ & $5.40 \pm 1.53$ & $1-7$ & S-E & .049 & 0.28 \\
\hline $\mathrm{E}$ & $4.95 \pm 1.67$ & $1-7$ & $\mathrm{~S}-\mathrm{N}$ & NS & 0.03 \\
\hline $\mathrm{N}$ & $5.44 \pm 1.36$ & $1-7$ & $\mathrm{E}-\mathrm{N}$ & .028 & 0.32 \\
\hline \multicolumn{6}{|l|}{ Pain frequency } \\
\hline $\mathrm{S}$ & $4.76 \pm 1.83$ & $1-7$ & S-E & NS & 0.20 \\
\hline $\mathrm{E}$ & $4.42 \pm 1.66$ & $1-7$ & $\mathrm{~S}-\mathrm{N}$ & NS & 0.17 \\
\hline $\mathrm{N}$ & $4.47 \pm 1.64$ & $1-7$ & $\mathrm{E}-\mathrm{N}$ & NS & 0.03 \\
\hline \multicolumn{6}{|l|}{ Disease frequency } \\
\hline $\mathrm{S}$ & $4.50 \pm 1.80$ & $1-7$ & S-E & NS & 0.13 \\
\hline $\mathrm{E}$ & $4.73 \pm 1.71$ & $1-7$ & $\mathrm{~S}-\mathrm{N}$ & .033 & 0.40 \\
\hline $\mathrm{N}$ & $5.17 \pm 1.59$ & $1-7$ & $\mathrm{E}-\mathrm{N}$ & NS & 0.27 \\
\hline
\end{tabular}

Note. $\quad$ Comp. $=$ comparison. $\mathrm{S}=$ students of sport sciences, $\mathrm{E}=$ students of education, $\mathrm{N}=$ students of natural sciences. NS $=$ not significant.

tend to be more open, critical, with a considerable level of self-confidence, use assertive behaviour, are well equipped with foreign languages and understand information technologies. On the other hand, these personality traits are balanced by smaller independence and responsibility (Linhartová, 2008). The main motivation factor of Czech students for enrolling in university is to achieve university education in order to have a successful professional career and a wellpaid job. Accompanying features of these factors are university degree and a good status in a society. The most frequent issues during the course of study include lack of finance, balancing occasional jobs and study, complicated commuting and taking exams and credit tests (Linhartová, 2008; Menclová \& Baštová, 2005).

The research sample of the present study consists of university students specializing in sport sciences, education and natural sciences. The study is mainly focused on the comparison of groups of students studying sport sciences compared to non-sporting sciences students. In this case, students of non-sporting disciplines are constituted of students studying the natural and educational sciences. Based on the analysis of the survey results, we can say that the comparison of students of natural and educational sciences shows relatively similar values and significant differences were not found. Both of these groups are almost comparable 
Table 4

Comparison of the subcomponents of satisfaction with own person in current university students with respect to study specialization

\begin{tabular}{|c|c|c|c|c|c|}
\hline Own person & Mean $\pm S D$ & Range & Comp. & $p$ & $d$ \\
\hline \multicolumn{6}{|c|}{ Abilities and skills } \\
\hline $\mathrm{S}$ & $5.31 \pm 1.03$ & $2-7$ & S-E & .013 & 0.29 \\
\hline $\mathrm{E}$ & $5.01 \pm 1.04$ & $1-7$ & $\mathrm{~S}-\mathrm{N}$ & .016 & 0.32 \\
\hline $\mathrm{N}$ & $4.97 \pm 1.06$ & $2-7$ & $\mathrm{E}-\mathrm{N}$ & NS & 0.04 \\
\hline \multicolumn{6}{|c|}{ Previous way of life } \\
\hline $\mathrm{S}$ & $5.40 \pm 1.21$ & $1-7$ & S-E & .015 & 0.28 \\
\hline $\mathrm{E}$ & $5.07 \pm 1.19$ & $1-7$ & $\mathrm{~S}-\mathrm{N}$ & .015 & 0.29 \\
\hline $\mathrm{N}$ & $5.06 \pm 1.13$ & $1-7$ & $\mathrm{E}-\mathrm{N}$ & NS & 0.00 \\
\hline \multicolumn{6}{|l|}{ Appearance } \\
\hline $\mathrm{S}$ & $5.25 \pm 1.28$ & $2-7$ & S-E & $<.001$ & 0.47 \\
\hline $\mathrm{E}$ & $4.65 \pm 1.27$ & $1-7$ & $\mathrm{~S}-\mathrm{N}$ & $<.001$ & 0.40 \\
\hline $\mathrm{N}$ & $4.75 \pm 1.25$ & $1-7$ & $\mathrm{E}-\mathrm{N}$ & NS & 0.08 \\
\hline \multicolumn{6}{|c|}{ Self-confidence and self-assurance } \\
\hline S & $5.02 \pm 1.45$ & $1-7$ & S-E & $<.001$ & 0.53 \\
\hline $\mathrm{E}$ & $4.22 \pm 1.53$ & $1-7$ & $\mathrm{~S}-\mathrm{N}$ & $<.001$ & 0.51 \\
\hline $\mathrm{N}$ & $4.28 \pm 1.47$ & $1-7$ & $\mathrm{E}-\mathrm{N}$ & NS & 0.04 \\
\hline \multicolumn{6}{|l|}{ Character } \\
\hline $\mathrm{S}$ & $5.51 \pm 1.04$ & $1-7$ & S-E & .030 & 0.29 \\
\hline $\mathrm{E}$ & $5.18 \pm 1.17$ & $1-7$ & $\mathrm{~S}-\mathrm{N}$ & .030 & 0.31 \\
\hline $\mathrm{N}$ & $5.16 \pm 1.19$ & $1-7$ & $\mathrm{E}-\mathrm{N}$ & NS & 0.02 \\
\hline \multicolumn{6}{|l|}{ Vitality } \\
\hline $\mathrm{S}$ & $5.74 \pm 1.10$ & $1-7$ & S-E & $<.001$ & 0.50 \\
\hline $\mathrm{E}$ & $5.16 \pm 1.30$ & $1-7$ & $\mathrm{~S}-\mathrm{N}$ & .001 & 0.45 \\
\hline $\mathrm{N}$ & $5.17 \pm 1.36$ & $1-7$ & $\mathrm{E}-\mathrm{N}$ & NS & 0.01 \\
\hline \multicolumn{6}{|c|}{ Ability to cope with others } \\
\hline $\mathrm{S}$ & $5.71 \pm 0.99$ & $3-7$ & S-E & NS & 0.15 \\
\hline $\mathrm{E}$ & $5.55 \pm 1.10$ & $1-7$ & $\mathrm{~S}-\mathrm{N}$ & NS & 0.20 \\
\hline $\mathrm{N}$ & $5.52 \pm 0.94$ & $2-7$ & $\mathrm{E}-\mathrm{N}$ & NS & 0.03 \\
\hline
\end{tabular}

Note. Comp. $=$ comparison. $\mathrm{S}=$ students of sport sciences, $\mathrm{E}=$ students of education, $\mathrm{N}=$ students of natural sciences. NS = not significant.

and appropriately represent the sample of students of non-sporting disciplines.

The results of the research indicate a possible correlation between lifestyle and study specializations. Specifically, the students of sport sciences reported the significantly highest values of overall life satisfaction compared with the students of education and natural sciences. The students of sport sciences are expected to have a higher proportion of physical activity and active lifestyle as a primary result of their study specialization that can correspond with the findings in the area of life satisfaction and its components. Sport and an optimum level of physical activity can be one of the significant factors contributing to overall quality of life and life satisfaction in current students (Bize, Johnson, \&
Plotnikoff, 2007; Blahutková, Janošková, \& Voráčová, 2012; Guven, Aysegul, Ozden, \& Fatma, 2013; Joseph et al., 2014; Mikolajczyk et al., 2008; Perales et al., 2014; Schnohr et al., 2005). Apart from the highest level of overall life satisfaction in the students of sport sciences, these students reported significantly higher subjective satisfaction in the area of health, satisfaction with own person and satisfaction in the sexual area compared with the students of education and natural sciences.

Subjective assessment of health by the students of sport sciences in various subcomponents indicates the highest level of satisfaction with their somatic health condition, mental and physical condition. These conclusions might correspond with an expected higher level 
Table 5

Comparison of life satisfaction in the area of sexuality in current university students with respect to study specialization

\begin{tabular}{|c|c|c|c|c|c|}
\hline Sexuality & Mean $\pm S D$ & Range & Comp. & $p$ & $d$ \\
\hline \multicolumn{6}{|c|}{ Physical attractiveness } \\
\hline $\mathrm{S}$ & $5.36 \pm 1.26$ & $1-7$ & S-E & $<.001$ & 0.47 \\
\hline $\mathrm{E}$ & $4.77 \pm 1.24$ & $1-7$ & $\mathrm{~S}-\mathrm{N}$ & $<.001$ & 0.57 \\
\hline $\mathrm{N}$ & $4.60 \pm 1.38$ & $1-7$ & E-N & NS & 0.14 \\
\hline \multicolumn{6}{|c|}{ Sexual performance } \\
\hline $\mathrm{S}$ & $5.53 \pm 1.14$ & $1-7$ & S-E & NS & 0.25 \\
\hline $\mathrm{E}$ & $5.23 \pm 1.26$ & $1-7$ & $\mathrm{~S}-\mathrm{N}$ & .014 & 0.31 \\
\hline $\mathrm{N}$ & $5.16 \pm 1.21$ & $1-7$ & $\mathrm{E}-\mathrm{N}$ & NS & 0.06 \\
\hline \multicolumn{6}{|c|}{ Sexual frequency } \\
\hline $\mathrm{S}$ & $5.03 \pm 1.55$ & $1-7$ & S-E & NS & 0.10 \\
\hline $\mathrm{E}$ & $4.87 \pm 1.56$ & $1-7$ & $\mathrm{~S}-\mathrm{N}$ & NS & 0.21 \\
\hline $\mathrm{N}$ & $4.69 \pm 1.64$ & $1-7$ & $\mathrm{E}-\mathrm{N}$ & NS & 0.11 \\
\hline \multicolumn{6}{|c|}{ Partner's behaviour } \\
\hline $\mathrm{S}$ & $5.26 \pm 1.65$ & $1-7$ & S-E & NS & 0.11 \\
\hline $\mathrm{E}$ & $5.43 \pm 1.56$ & $1-7$ & $\mathrm{~S}-\mathrm{N}$ & NS & 0.12 \\
\hline $\mathrm{N}$ & $5.06 \pm 1.68$ & $1-7$ & $\mathrm{E}-\mathrm{N}$ & NS & 0.23 \\
\hline \multicolumn{6}{|c|}{ Sexual reaction } \\
\hline $\mathrm{S}$ & $5.52 \pm 1.25$ & $1-7$ & S-E & NS & 0.22 \\
\hline $\mathrm{E}$ & $5.24 \pm 1.27$ & $1-7$ & $\mathrm{~S}-\mathrm{N}$ & NS & 0.20 \\
\hline $\mathrm{N}$ & $5.28 \pm 1.22$ & $1-7$ & $\mathrm{E}-\mathrm{N}$ & NS & 0.03 \\
\hline \multicolumn{6}{|c|}{ Openness in communication } \\
\hline $\mathrm{S}$ & $5.65 \pm 1.24$ & $1-7$ & S-E & NS & 0.23 \\
\hline $\mathrm{E}$ & $5.36 \pm 1.30$ & $1-7$ & $\mathrm{~S}-\mathrm{N}$ & .006 & 0.35 \\
\hline $\mathrm{N}$ & $5.20 \pm 1.30$ & $1-7$ & $\mathrm{E}-\mathrm{N}$ & NS & 0.12 \\
\hline \multicolumn{6}{|c|}{ Agreement with partner } \\
\hline $\mathrm{S}$ & $5.40 \pm 1.51$ & $1-7$ & S-E & NS & 0.10 \\
\hline $\mathrm{E}$ & $5.54 \pm 1.44$ & $1-7$ & $\mathrm{~S}-\mathrm{N}$ & NS & 0.01 \\
\hline $\mathrm{N}$ & $5.42 \pm 1.33$ & $1-7$ & $\mathrm{E}-\mathrm{N}$ & NS & 0.09 \\
\hline
\end{tabular}

Note. Comp. = comparison. $\mathrm{S}=$ students of sport sciences, $\mathrm{E}=$ students of education, $\mathrm{N}=$ students of natural sciences. NS $=$ not significant.

of physical fitness, which represents a significant health and wellbeing dimension (Bize, Johnson, \& Plotnikoff, 2007; Grant, Wardle, \& Steptoe, 2009; Guven et al., 2013; Mikolajczyk et al., 2008; Schnohr et al., 2005). To express personal wellbeing in the context of physical and mental health, the wellness concept might be used that relates to adopting certain behaviour and lifestyle. Such behaviour includes stress coping, healthy nutrition, non-smoking, adequate sleep and regular physical activity. At the same time, this type of behaviour can be expected in the students of sport sciences. This context explains the significantly higher subjectively perceived health and its subcomponents in the students of sport sciences in comparison with the students of education and natural sciences. The principal difference in perceiving health in the monitored sample of students is represented by physical activity as a part of lifestyle and daily routine. In the students of sport sciences, regular physical activity is included in the study course itself. This is contrary to the students of other specializations, whose study is not physically demanding and the level of their regular physical activity can be at a minimum. Provided that physical activity has an overall positive effect on personal wellbeing, it will also influence the overall level of life satisfaction and its components (Netz, Wu, Becker, \& Tenenbaum, 2005; Ogden, 2012; Ruseski, Humphreys, Hallman, Wicker, \& Breuer, 2014).

Similarly to health, the students of sport sciences reported a significantly higher level of satisfaction 
with own person - self-evaluation. Particularly the subcomponents of satisfaction with appearance, selfconfidence and self-assurance, abilities and skills, and vitality significantly saturate the overall level of satisfaction with own person in the students of sport sciences. Self-evaluation is a source of life success of an individual, his/her social position and prestige (Kwan, Love, Ryff, \& Essen, 2003). Self-image/self-conception is developed on the basis of interaction experience (Hogg, 2000). In the students of sport sciences the awareness of "oneself" is significantly subjected by the "physical oneself", which can be understood as awareness of a physical difference from the outer environment. Based on a body scheme a body image is created. In this context, an individual takes specific attitudes to own body and its parts. These are affected by satisfaction with own appearance. The body image is defined as a method in which a person thinks about, perceives and feels own body (Grogan, 2008; Swami, Steadman, \& Tovée, 2009). This particularly includes the estimation of body size (perception), assessment of body attractiveness (thought) and emotions associated with the shape and size of the body (feelings). In the process of experiencing, assessment and perception of own body, own experiences, wishes, expectations and perceptions of the surrounding world are considered. Own body and its proportions are compared with other people and considered in the context of existing stereotypes of womanliness, manliness, beauty and health and also with respect to the constantly changing media images. Based on an individual's subjective selfevaluation, an image of satisfaction or dissatisfaction with oneself is developed (Grogan, 2008). Hrachovinová, Csémy, and Chudobová (2005) note that our population largely suffers from a body image disorder; specifically in the area of subjective dissatisfaction with own body proportions, weight and appearance. Considering the facts above, the observed significant differences in higher satisfaction with own person and its subcomponents in the students of sport sciences relate particularly to the area associated with perceiving own physical characteristics. In general, self-conception has a unifying role in human interaction with the environment, and adaptation to changing conditions. In this context we can comment on the resulting values in the subcomponent of self-confidence and self-assurance in the students of physical culture, which are significantly higher compared with the students of education and natural sciences. Also, an analysis of sources saturating the feeling of own value (results of own activities, opinions of others, position within a group, appearance, self-estimation) supports the present findings. In most cases, the students of sport sciences know a feeling of success based on objective results of their activities.
With respect to their sports genesis, they might have experience with opinions of others in terms of expressing agreement, admiration and respect (Fox, 2000; Lowery et al., 2005). They often work in a group, take a certain position that increases the feeling of own value and respect. As a result of regular physical activity, their physical appearance is positively formed, which affects the degree of self-estimation. This context explains the observed differences in the area of satisfaction with own person in the students of sport sciences compared with the students of education and natural sciences.

Another significant area of life satisfaction in young adults is sexuality, which is a natural and important part of the human being (Bancroft, 2009; LeVay \& Baldwin, 2012). For most individuals, university study and related lifestyle represents a period, during which sexuality comes to the forefront. Sexual behaviour represents a significant variable in the life of young adults and is an important part of psychosocial health determinants (Ogden, 2012). At the same time however, during the period of young adulthood, individuals report the highest number of sexual partners (Crooks \& Baur, 2010). Therefore, sexual behaviour of individuals in this age category should fulfil the principles of healthy sexual life with respect to further personality development and various health components. In our samples, the highest life satisfaction in the area of sexuality was reported by the student of sport sciences. In comparison with the students of natural sciences the difference is significant. A detailed analysis of individual sexuality subcomponents revealed minimum differences between various groups of students. In most cases the differences are insignificant both statistically and effect size is small. Only in the component of physical attractiveness a significantly higher value was identified in the students of sport sciences compared with the students of education and natural sciences. Higher values in the area of somatic dispositions in the students of sport sciences are reflected in the components related to health and self-evaluation. In the area of sexuality in current university students there is a certain trend of a higher level of satisfaction in the students of sport sciences. In general however, the level of life satisfaction in the area of sexuality in the monitored university students can be assessed satisfactory. Satisfaction in the area of sexuality and sexual behaviour in young adulthood (which is the age period of our sample) presents a significant component of overall life satisfaction and quality of life (Higgins, Mullinax, Trussell, Davidson, $\&$ Moore, 2011). Healthy sexual life of young adults also allows full understanding of sexual orientation, sexual preferences, or a transfer from status partnerships into intimate and mature relationships. In case of a mature partnership based on intimacy, all principal 
health components can be satisfied in young adults physical, mental, social and spiritual (Crooks \& Baur, 2010; LeVay \& Baldwin, 2012; Ogden, 2012). Sexuality and adequate sexual behaviour thus represents a significant part of health and healthy lifestyle enriches the database of scientific data on specific individuals of various study specializations.

The facts described above can affect the subjectively perceived personal wellbeing reflected in the overall level of quality of life, life satisfaction and subsequently the health in current university students. The present study reveals that current university students of sport sciences assess their level of life satisfaction significantly higher compared with the students of other specializations. Sports and physical activity in university students thus represent significant components contributing to a higher level of quality of life and life satisfaction (Blahutková, Janošková, \& Voráčová, 2012).

\section{Study limitations}

The present findings can be influenced by gender disproportion, particularly the significantly higher number of women from the Faculty of Education. In scientific sources we can observe inconsistent conclusions with respect to quality of life and life satisfaction (Ye, Yu, \& Li, 2012; Zhang \& Leung, 2002). Some studies report a higher level of life satisfaction for men (Moksnes \& Espnes, 2013; Ye, Yu, \& Li, 2012), while some studies report higher levels of life satisfaction in women (Ruseski et al., 2014; Schoon, Hansson, \& Salmela-Aro, 2005). Rodná and Rodný (2001) report that the effect of gender on overall life satisfaction is insignificant. In general, it appears that gender differences in life satisfaction are the most evident in the areas of health, finances and family life (Daig et al., 2009). Women are usually the most satisfied in the area connected with family and with their own children (Beutel, Glaesmer, Decker, Fischbeck, \& Brähler, 2009). Also, for college students the effect of gender is considered as a factor affecting the level of life satisfaction (Huo \& Kong, 2014). The possible influence of gender on the issues of life satisfaction in university students is a topic for a separate study. Another possible limitation of the present findings of this study can be influenced by the cohort effect.

The strengths of the present study are the findings based on a relatively high number of probands of current university population of various study specializations. A significant factor with respect to practical implementation of the present findings is a transfer to the area of university psychological counselling. This represents a separate psychological area, where the results of the study can be used in work with the defined target group. Specifically the study results can be used in different areas of teaching and counselling. At the same time it can be used in individual work with students in the process of lifestyle changes with the aim of maintaining a positive long-term adherence and good health.

\section{Conclusions}

The present study reveals that current university students of sports sciences assess their life satisfaction significantly higher compared with the students of other study specializations.

The results of the study indicate a positive correlation between possible active lifestyle, whose important part is physical activity, in current university students of sport sciences and the subjectively perceived level of life satisfaction, health, self-evaluation and sexuality. Sports and physical activity in university students thus represent a significant component that contributes particularly to increased quality of life and overall healthy lifestyle.

\section{References}

Adlaf, E. M., Gliksman, L., Demers, A., \& Newton-Taylor, B. (2001). The prevalence of elevated psychological distress among Canadian undergraduates: Findings from the 1998 Canadian Campus Survey. Journal of American College Health, 50, 67-72.

Bancroft, J. (2009). Human sexuality and its probleme. London: Churchill Livingstone.

Batrymbetova, S. A. (2008). The medical social factors of students' health. Problemy sotsialnoi gigieny $i$ istoriia meditsiny, 5, 9-11.

Beutel, M. E., Glaesmer, H., Decker, O., Fischbeck, S., \& Brähler, E. (2009). Life satisfaction, distress, and resiliency across the life span of women. Menopause, 16, 1132-1138.

Bize, R., Johnson, J. A., \& Plotnikoff, R. C. (2007). Physical activity level and health-related quality of life in the general adult population: A systematic review. Preventive Medicine, 45, 401-415.

Blahutková, M., Janošková, H., \& Voráčová, K. (2012). Sport jako prvek kvality života u vysokoškolských studentů [Sport as an element of quality of life among university students]. In V. Blahutková \& V. Pacholík (Eds.), Sborník konference Psychologie sportu v praxi 2012 (pp. 27-37). Brno: Masarykova univerzita.

Cohen, J. (1988). Statistical power analysis for the behavioral sciences (4th ed.). New York, NY: Academic Press.

Cortina, J. M., \& Nouri, H. (2000). Effect size for ANOVA design. Thousand Oaks, CA: Sage publications.

Crooks, R., \& Baur, K. (2010). Our sexuality. Belmont, CA: Wadsworth.

Daig, I., Herschbach, P., Lehmann, A., Knoll, N., \& Decker, O. (2009). Gender and age differences in domain-specific 
life satisfaction and the impact of depressive and anxiety symptoms: A general population survey from Germany. Quality of Life Research, 18, 669-678.

Dunn, A. L., Trivedi, M. H., \& O’Neal, H. A. (2001). Physical activity dose-response effects on outcomes of depression and anxiety. Medicine \& Science in Sports \& Exercise, 33, 587-597.

Dyrbye, L. N., Thomas, M. R., \& Shanafelt, T. D. (2006). Systematic review of depression, anxiety, and other indicators of psychological distress among U. S. and Canadian medical students. Academic Medicine, 81, 354-373.

Fahrenberg, J., Myrtek, M., Schumacher, J., \& Brähler, E. (2000). Fragebogen zur Lebenszufriedenheit (FLZ) [The life satisfaction questionnaire]. Göttingen: Hogrefe.

Fox, K. R. (2000). Self-esteem, self-perceptions, and exercise. International Journal of Sport and Exercise Psychology, 31, 228-240.

Frederick, D., Peplau, L., \& Lever, J. (2006). The swimsuit issue: Correlates of body image in a sample of 52,677 heterosexual adults. Body Image, 3, 413-419.

Geoff, P., Lovell, G. P., El Ansari, W., \& Parker, J. K. (2010). Perceived exercise benefits and barriers of non-exercising female university students in the United Kingdom. International Journal of Environmental Research and Public Health, 7, 784-798.

Grant, N., Wardle, J., \& Steptoe, A. (2009). The relationship between life satisfaction and health behavior: A crosscultural analysis of young adults. International Journal of Behavioral Medicine, 16, 259-268.

Grogan, S. (2008). Body image: Understanding body dissatisfaction in men, women and children. Hove: Routledge.

Guven, D. S., Aysegul, O., Ozden, T., \& Fatma, A. (2013). The relationship between health college students physical activity and life satisfaction. International Journal of Academic Research, 5, 327-331.

Hamaideh, S. H. (2011). Stressors and reactions to stressors among university students. International Journal of Social Psychiatry, 57, 69-80.

Higgins, J. A., Mullinax, M., Trussell, J., Davidson, J. K. Sr., \& Moore, N. B. (2011). Sexual satisfaction and sexual health among university students in the United States. American Journal of Public Health, 101, 1643-1654.

Hogg, M. A. (2000). Subjective uncertainty reduction through self-categorization: A motivational theory of social identity processes. European Review of Social Psychology, 11, 223-255.

Hrachovinová, T., Csémy, L., \& Chudobová, P. (2005). Psychologický kontext spokojenosti s vlastním tělem u VŠ studentů [Psychological context of satisfaction with own body in university students]. Czechoslovak Psychology, 49, 9-18.

Huo, Y., \& Kong, F. (2014). Moderating effects of gender and loneliness on the relationship between self-esteem and life satisfaction in Chinese university students. Social Indicators Research, 118, 305-314.

Joseph, R. P., Royse, K. E., Benitez, T. J., \& Pekmezi, D. W. (2014). Physical activity and quality of life among university students: Exploring self-efficacy, self-esteem, and affect as potential mediators. Quality of Life Research, 23, 659-667.
Kahneman, D., Diener, E., \& Schwarz, N. (Eds.). (2003). Well-being: Foundations of hedonic psychology. New York, NY: Russel Sage Foundation.

Kirkcaldy, B. D., Shephard, R. J., \& Siefen, R. G. (2002). The relationship between physical activity and selfimage and problem behaviour among adolescents. Social Psychiatry and Psychiatric Epidemiology, 37, 544-550.

Kwan, C. M. L., Love, G. D., Ryff, C. D., \& Essen, M. J. (2003). The role of self-enhancing evaluations in a successful life transition. Psychology and Aging, 18, 3-12.

LeVay, S., \& Baldwin, J. (2012). Human sexuality. Sunderland, MA: Sinauer Associates, Inc.

Linhartová, D. (2008). Vysokoškolská psychologie [University psychology]. Brno: Mendelova zemědělská a lesnická univerzita.

Lowery, S. E., Kurpius, S. E. R., Befort, Ch., Blanks, E. H., Sollenberger, S., Nicpon, M. F., \& Huser, L. (2005). Body image, self-esteem, and health-related behaviors among male and female first year college students. Journal of College Student Development, 46, 612-623.

Martikainen, L. (2009). Life satisfaction of university-educated young adults. In A. Makinen \& P. Hájek (Eds.), Psychology of Happiness (chapter 7, pp. 1-15). Helsinki: Nova Science.

Menclová, L., \& Baštová, J. (2005). Vysokoškolský student $v$ České republice roku 2005 [A university student in the Czech Republic in 2005]. Prague: MŠMT.

Mikolajczyk, R. T., Brzoska, P., Maier, C., Ottova, V., Meier, S., Dudziak, U., ... El Ansari, W. (2008). Factors associated with self-rated health status in university students: A cross-sectional study in three European countries. BMC Public Health, 8, 215.

Moksnes, U. K., \& Espnes, G. A. (2013). Self-esteem and life satisfaction in adolescents-gender and age as potential moderators. Quality of Life Research, 22, 2921-2928.

Netz, Y., Wu, M. J., Becker, B. J., \& Tenenbaum, G. (2005). Physical activity and psychological well-being in advanced age: A meta-analysis of intervention studies. Psychology and Aging, 20, 272-284.

Ogden, J. (2012). Health psychology. Berkshire: McGraw-Hill.

Penedo, F. J., \& Dahn, J. R. (2005). Exercise and well-being: A review of mental and physical health benefits associated with physical activity. Behavioural Medicine, 18, 189-193.

Perales, F., del Pozo-Cruz, J., del Pozo-Cruz, J., \& del PozoCruz, B. (2014). On the associations between physical activity and quality of life: Findings from an Australian nationally representative panel survey. Quality of Life Research, 23, 1921-1933.

Piko, B. F., \& Keresztes, N. (2006). Physical activity, psychosocial health and life goals among youth. Journal of Community Health, 31, 136-145.

Proctor, C. L., Linley, P. A., \& Maltby, J. (2009). Youth life satisfaction: A review of the literature. Journal of Happiness Studies, 10, 583-630.

Roberts, R., Golding, J., Towell, T., \& Weinreb, I. (1999). The effects of economic circumstances on British students' mental and physical health. Journal of American College Health, 48, 103-109.

Rodná, K., \& Rodný, T. (2001). Dotazník životní spokojenosti [The life satisfaction questionnaire]. Prague: Testcentrum.

Ruseski, J. E., Humphreys, B. R., Hallman, K., Wicker, P., \& Breuer, C. (2014). Sport participation and subjective 
well-being: Instrumental variable results from German survey data. Journal of Physical Activity and Health, 11, 396-403.

Ryan, R. M., \& Deci, E. L. (2000). Self-determination theory and the facilitation of intrinsic motivation, social development, and well-being. American Psychologist, 55, 68-78.

Schnohr, P., Kristensen, T. S., Prescott, E., \& Scharling, H. (2005). Stress and life dissatisfaction are inversely associated with jogging and other types of physical activity in leisure time - The Copenhagen City Heart Study. Scandinavian Journal of Medicine \& Science in Sports, 15, 107-112.

Schoon, I., Hansson, L., \& Salmela-Aro, K. (2005). Combining work and family life: Life satisfaction among married and divorced men and women in Estonia, Finland, and the UK. European Psychologist, 10, 309-319.

Stallman, H. M. (2008). Prevalence of psychological distress in university students - implications for service delivery. Australian Family Physician, 37, 673-677.
Swami, V., Steadman, L., \& Tovée, M. J. (2009). A comparison of body size ideals, body dissatisfaction, and media influence between female track athletes, martial artists, and non-athletes. Psychology of Sport and Exercise, 10, 609-614.

Thomas, J. R., Nelson, J. K., \& Silverman, S. J. (2011). Research methods in physical activity (6th ed.). Champaign, IL: Human Kinetics.

Ye, S., Yu, L., \& Li, K. (2012). A cross-lagged model of selfesteem and life satisfaction: Gender differences among Chinese university students. Personality and Individual Differences, 52, 546-551.

Zhang, L., \& Leung, J. (2002). Moderating effects of gender and age on the relationship between self-esteem and life satisfaction in mainland Chinese. International Journal of Psychology, 37, 83-91. 